\title{
Characteristics and Factors Associated with SARS-CoV-2 Infections in Individuals That Attended Referral Hospitals from Southern Region of Bahia State, Brazil: A Surveillance Network Retrospective Study
}

\author{
Fabrício Barbosa Ferreira ${ }^{1,2}$, Galileu Barbosa Costa ${ }^{1,2, *(\mathbb{D})}$, Anaiá da Paixão Sevá ${ }^{3}$ (D), \\ George Rego Albuquerque 1,3 ${ }^{\mathbb{D}}$, Ana Paula Melo Mariano 1,4 ${ }^{\mathbb{D}}$, Amanda Teixeira Sampaio Lopes 1,3, \\ Hllytchaikra Ferraz Fehlberg 1,3 (D), Íris Terezinha Santos de Santana 1,4 , Pérola Rodrigues dos Santos 1,4, \\ Luciano Cardoso Santos 1,3 $\mathbb{D}$, Laine Lopes Silva de Jesus 1,4, Renato Fontana 1,4, Bianca Mendes Maciel 1,4 ${ }^{1}$, \\ Mylene de Melo Silva ${ }^{1}$, Luane Etienne Barreto ${ }^{1,3}$ and Sandra Rocha Gadelha ${ }^{1,4, *}$
}

1 Laboratório de Farmacogenômica e Epidemiologia Molecular, Departamento de Ciências Biológicas, Universidade Estadual de Santa Cruz, Ilhéus 45662-900, Bahia, Brazil; fabriciob.lisboa@hotmail.com (F.B.F.); gralbu@uesc.br (G.R.A.); apm.mariano@hotmail.com (A.P.M.M.); amanda_tsl@yahoo.com.br (A.T.S.L.);

check for

updates

Citation: Ferreira, F.B.; Barbosa Costa, G.; Sevá, A.d.P.; Albuquerque, G.R.; Mariano, A.P.M.; Sampaio

Lopes, A.T.; Fehlberg, H.F.; Santos de Santana, Í.T.; dos Santos, P.R.; Santos, L.C.; et al. Characteristics and Factors Associated with SARS-CoV-2 Infections in Individuals That Attended Referral Hospitals from Southern Region of Bahia State, Brazil: A Surveillance Network Retrospective Study. Viruses 2021, 13, 2462.

https://doi.org/10.3390/v13122462

Academic Editor: Oliver Schildgen

Received: 1 September 2021

Accepted: 25 October 2021

Published: 9 December 2021

Publisher's Note: MDPI stays neutral with regard to jurisdictional claims in published maps and institutional affiliations.

Copyright: (c) 2021 by the authors. Licensee MDPI, Basel, Switzerland. This article is an open access article distributed under the terms and conditions of the Creative Commons Attribution (CC BY) license (https:/ / creativecommons.org/licenses/by/ $4.0 /)$. ferrazhellen@hotmail.com (H.F.F.); iristerezinha@gmail.com (Í.T.S.d.S.); prsantos.bio@uesc.br (P.R.d.S.); luciano.cardoso23@hotmail.com (L.C.S.); 1lsjesus.bio@uesc.br (L.L.S.d.J.); rfontana@uesc.br (R.F.); bmmaciel@uesc.br (B.M.M.); mmsilva@uesc.br (M.d.M.S.); luaneetienne@hotmail.com (L.E.B.)

2 Departamento de Ciências da Saúde, Universidade Estadual de Santa Cruz, Ilhéus 45662-900, Bahia, Brazil

3 Departamento de Ciências Agrárias e AmBientais, Universidade Estadual de Santa Cruz, Ilhéus 45662-900, Bahia, Brazil; apseva@uesc.br

4 Departamento de Ciências Biológicas, Universidade Estadual de Santa Cruz, Ilhéus 45662-900, Bahia, Brazil

* Correspondence: galileuk1@gmail.com (G.B.C.); srgmello@uesc.br (S.R.G.); Tel.: +55-73-3680-5155 (G.B.C. \& S.R.G.)

Abstract: In December 2019, a novel coronavirus was detected in Wuhan, China, and rapidly spread worldwide. In Brazil, to date, there have been more than 20,000,000 confirmed cases of COVID-19 and more than 550,000 deaths. The purpose of the current study was to determine the clinical and epidemiological profile of the population affected by COVID-19 that have attended referral hospitals in Southern region of Bahia State, to better understand the disease and its risk factors in order to enable more appropriate conduct for patients. An observational, descriptive, crosssectional, exploratory study was conducted using secondary data collected from the Laboratório de Farmacogenômica e Epidemiologia Molecular, Universidade Estadual de Santa Cruz (LAFEM/UESC). Chi-squared and Fisher's exact tests were applied to determine the association between clinical symptoms and laboratory results, and to identify risk factors associated with SARS-CoV-2 infection. A total of 3135 individuals with suspected severe respiratory illness were analyzed and $41.4 \%$ of them tested positive for SARS-CoV-2 infection. Male individuals and having comorbidities were risk factors significantly associated with SARS-CoV-2 infection ( $\mathrm{OR}=1.17$ and $\mathrm{OR}=1.37$, respectively). Interestingly, being a healthcare professional was a significantly protective factor $(\mathrm{OR}=0.81, p<0.001)$. Our findings highlight the importance of routinely testing the population for early identification of infected individuals, and also provide important information to health authorities and police makers to improve control measures, management, and screening protocols.

Keywords: SARS-CoV-2; COVID-19; epidemiology; risk factors; healthcare professionals; Brazil

\section{Introduction}

The coronavirus disease 2019 (COVID-19), caused by the novel severe acute respiratory syndrome coronavirus 2 (SARS-CoV-2), emerged in Wuhan, China, in December 2019 [1]. It rapidly spread and received pandemic status from the World Health Organization (WHO) on 11 March 2020 [2,3]. In Brazil, the first officially registered COVID-19 case occurred on 
26 February 2020 [4], and to date, there have already been more than 20,000,000 confirmed cases of COVID-19 in the country, with the number of deaths reaching more than 550,000 as of September 2021 [5].

Although most affected individuals may remain asymptomatic, the severity of COVID19 can range from mild symptoms to severe illness [6]. The most common clinical symptoms are fever, cough, dyspnea, and myalgia [7], and there may also be diarrhea and sensory disorders, such as smell and taste [8-10]. It is important to point out that some of the affected individuals (10-20\%) can progress to more critical outcomes, including severe pneumonia and respiratory failure, which requires hospitalization $[7,11]$.

Individuals at risk of severe illness and death include elderly people and those with underlying conditions, such as hypertension, diabetes, obesity, chronic cardiovascular and respiratory disease, and cancer [6,7,11-14]. However, individuals from all age groups and with no history of comorbidities can also be severely affected [11-15]. Furthermore, males experience higher complications due to COVID-19 disease, although no differences in the proportion of males and females infected with SARS-CoV-2 has been observed [16].

During the pandemic, several preventive measures were put in place by public health authorities to track and contain the spread of SARS-CoV-2, and to care for those individuals presenting severe illness $[17,18]$. The opening of new clinical and Intensive Care Units (ICU), the implementation of field hospitals, as well as maintaining and enhancing the healthcare workforce to fight against the COVID-19 crisis are some examples. Indeed, healthcare professionals working on the front line are at high risk of infection, also being included in routine tests for early SARS-CoV-2 detection [19]. Furthermore, there have also been investments applied to increase the diagnostic capacity through new laboratories and complementary support by research laboratories from public universities [20].

Here, we aimed to characterize the clinical and epidemiological profile of individuals that attended different referral hospital networks from the Southern region of Bahia State, Brazil, also identifying the spectrum of risk factors for SARS-CoV-2 infection among frontline healthcare professionals. In addition, this study represents an opportunity to contribute to early identification of cases, avoiding or minimizing more severe outcomes related to COVID-19.

\section{Materials and Methods}

\subsection{Study Design and Data Curation}

An observational, descriptive, cross-sectional, exploratory study was conducted using secondary data from Laboratório de Farmacogenômica e Epidemiologia Molecular (LAFEM) database, located at Universidade Estadual de Santa Cruz (UESC). LAFEM/UESC works in partnership with the Central Public Health Laboratory Professor Gonçalo Moniz (LACEN-BA) and complementarily supports the routine diagnostics for SARS-CoV-2 detection in Southern region of Bahia State, which is one of the main epicenters of the COVID-19 pandemic after the capital Salvador and its metropolitan region.

During July to December 2020, a total of 3135 individuals with suspected severe respiratory illness were enrolled in this study, in which 541 were healthcare professionals. We included information from individuals that attended different referral hospitals in Southern region of Bahia State, which are Hospital Regional Costa do Cacau (HRCC) and

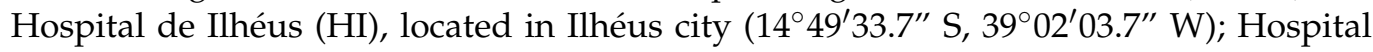
Calixto Midlej Filho (HCM), and Hospital de Base Luis Eduardo Magalhães (HBLEM) located in Itabuna city $\left(14^{\circ} 47^{\prime} 08^{\prime \prime} \mathrm{S}, 39^{\circ} 16^{\prime} 49^{\prime \prime} \mathrm{W}\right)$. Ilhéus and Itabuna are the third and the fifth largest cities in Bahia State, respectively, and reference centers in healthcare assistance for a large population located in the surroundings, as well as for leisure and commerce. Variables such as gender, age, self-reported skin color, clinical symptoms, comorbidities, and occupation were analyzed. 


\subsection{Laboratory Diagnosis}

Nasopharyngeal swab specimens collected from study participants were tested at LAFEM/UESC. Viral RNA was obtained by using an automated Loccus EXTRACTA 32 device and a MVXA-P016 extraction kit. To detect SARS-CoV-2 RNA a RT-qPCR targeting regions of envelope (E), RNA-dependent RNA polymerase (RdRp), and nucleocapsid protein $(\mathrm{N})$ genes were performed using the Allplex ${ }^{\mathrm{TM}}$ 2019-nCoV assay (Seegene ${ }^{\circledR}$, Seoul, Korea) [21]. We also performed another RT-qPCR targeting N1 and N2 genes using the CDC 2019-Novel Coronavirus (2019-nCoV) Real-Time RT-PCR Diagnostic Panel [22], according to the manufacturer's protocol.

\subsection{COVID-19 Symptoms Assessment}

A Chi-squared test with significance level of $5 \%(p \leq 0.05)$ was applied to determine the association between the frequency of each reported clinical symptom and the results of RT-qPCR. To calculate the prevalence of clinical symptoms for different age groups, a $95 \%$ confidence interval was applied. The proportions of the agreements, positive and negative, between the clinical symptoms were calculated according to Cunningham and co-workers [23]. All analyses were performed using the R software version 3.6.1 [24].

\subsection{Assessment of the Period of Symptoms until Laboratory Testing}

Comparative analysis between the period from the onset of symptoms until the laboratory diagnosis (in individuals that tested positive or not for SARS-CoV-2) was performed using the Wilcoxon test after verifying the non-normality of data. A $p$ value $<0.05$ was considered to be significant. As COVID-19 is more severe in older individuals, a correlation analysis was performed between the period of symptoms until the laboratory tests and patient's age. All analyses were performed using the R software version 3.6.1 [24].

\subsection{Assessment of Factors Associated with SARS-CoV-2 Infection}

To identify risk factors associated with SARS-CoV-2 infection, a bivariate analysis was carried out using Chi-squared and Fisher's exact tests. Variables with a significance level of $p<0.20$ were considered candidates to fit in the multivariate model, including all biologically plausible two-way interactions. A backwards approach was used and the best model was defined as the one that included significantly associated variables $(p<0.05)$ and minimized the value of the Akaike Information Criterion (AIC). Univariate analyzes were performed for variables that did not enter in the multivariate analysis. The proposed models were applied to all individuals. To minimize eventual bias, we also applied a separated model for healthcare professionals (HP) and the general public (excluding HP). Variables with less than $75 \%$ of the response rate and individuals with inconclusive results were excluded from the analysis. All analyses were performed using the $\mathrm{R}$ software version 3.6.1 [24].

\subsection{Ethical Considerations}

This study was submitted at Plataforma Brasil (a national and unified database of research records involving human beings for the entire Ethics in Research Committee/National Commission for Research Ethics, CEP/CONEP system) and approved by Research Ethics Committee of Universidade Estadual de Santa Cruz under registration number CAAE: 39142720.5.0000.5526.

\section{Results}

\subsection{Demographic Characteristics of Study Population}

During July to December 2020, a total of 3135 individuals with suspected COVID19 underwent molecular detection of SARS-CoV-2 (Table 1). The majority of surveyed participants were female (54.3\%) and the median age was 50 years (ranging from 1 to 103 years). Thirty-three samples $(1.05 \%)$ had inconclusive results and were consequently removed from subsequent analyses. Among the samples that had satisfactory results 
( $n=3102)$, a total of $1285(41.4 \%)$ tested positive for SARS-CoV-2 infection. Regarding the origin, most individuals (61.9\%) were from Itabuna city. Only $21.5 \%$ of the individuals were from Ilhéus, and the remaining $26.5 \%$ were from the surrounding municipalities such as Canavieiras, Itajuípe, Uruçuca, Buerarema, Aurelino Leal, Itacaré, Camacan, Itapé, Coaraci, and Ibicaraí.

Table 1. Frequency of analyzed individuals per hospital and according to RT-qPCR test for SARSCoV-2 detection.

\begin{tabular}{ccccc}
\hline \multirow{2}{*}{ Hospital } & \multicolumn{2}{c}{ Satisfactory Results } & \multirow{2}{*}{ Total } & \multirow{2}{*}{ Inconclusive } \\
\cline { 2 - 3 } & Positive (\%) & Negative (\%) & & \\
\hline $\begin{array}{c}\text { Hospital de Base Luis } \\
\text { Eduardo Magalhães } \\
\quad \text { (HBLEM) }\end{array}$ & $296(30.4)$ & $677(69.6)$ & 973 & 14 \\
$\begin{array}{c}\text { Hospital Calixto Midlej Filho } \\
\text { (HCM) }\end{array}$ & $371(43.6)$ & $479(56.4)$ & 850 & 6 \\
$\quad$ Hospital de Ilhéus (HI) & $142(41.2)$ & $203(58.8)$ & 345 & 1 \\
$\begin{array}{c}\text { Hospital Regional Costa do } \\
\text { Cacau (HRCC) }\end{array}$ & $476(50.9)$ & $458(49.1)$ & 934 & 12 \\
\hline
\end{tabular}

Figure 1 displays the frequency of individuals that tested positive for SARS-CoV-2. In general, male individuals were mostly affected, with a higher frequency among individuals aged 50-90 years. However, female individuals between 31 and 50 years were also highly affected.

\section{POPULATION PYRAMID IN FREQUENCY}

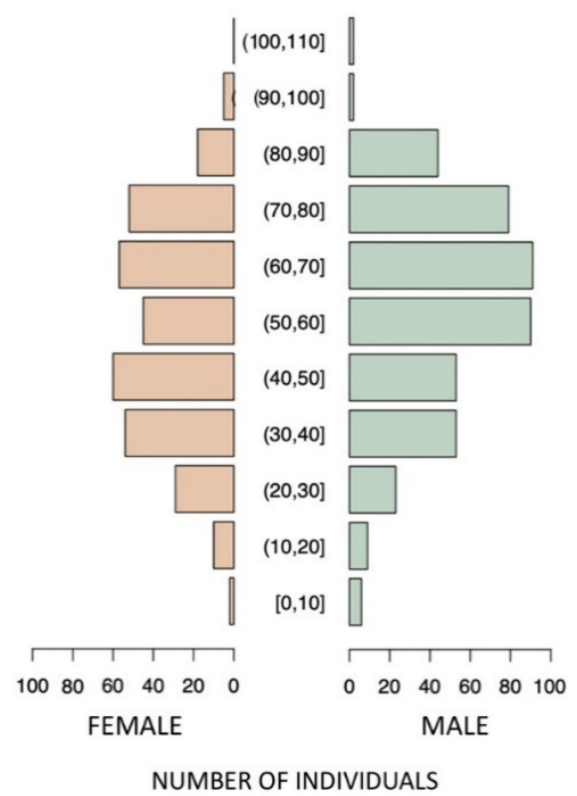

Figure 1. Frequency of individuals that tested positive for SARS-CoV-2 infection according to different age groups.

\subsection{Occupational Status of Study Participants}

For those individuals with satisfactory results of RT-qPCR, only $804(25.9 \%)$ had information regarding their occupational status, in which $67.3 \%(541 / 804)$ were healthcare professionals. Among those healthcare professionals that tested positive for SARS-CoV-2, the highest frequency was observed in nurse technicians (including fellows or interns) $(50.8 \% ; n=100)$ and nurses $(26.0 \% ; n=51)$. Other healthcare professionals' categories that tested positive for SARS-CoV-2 had frequencies lower than 10\% (Figure 2). 


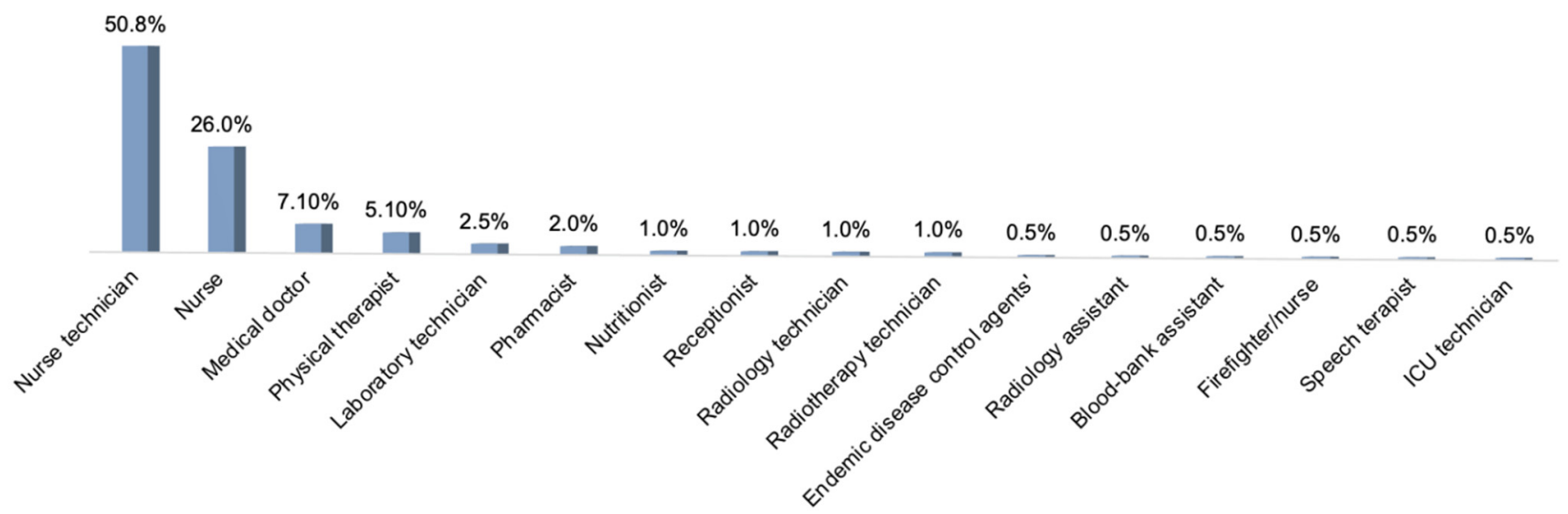

Figure 2. Frequency of reported occupational status of individuals that tested positive for SARS-CoV-2 infection.

\subsection{Characterization of Clinical Symptoms}

The most frequent symptoms reported by those individuals that tested positive for SARS-CoV-2 infection were fever, dyspnea, dry cough, and pharyngalgia (Figure 3). A comparative analysis between the main reported symptoms and results for SARS-CoV2 infection is presented in Table 2. All symptoms were statistically different between individuals that tested positive and negative for SARS-CoV-2 infection. Failure to present or report all symptoms was more frequent in the negative group $(p<0.001)$.

Table 2. Frequency of reported symptoms among individuals tested for SARS-CoV-2 infection.

\begin{tabular}{|c|c|c|c|c|c|}
\hline \multirow{2}{*}{ Symptoms } & \multicolumn{2}{|c|}{ RT-qPCR for SARS-CoV-2 } & \multicolumn{3}{|c|}{ Qui-Squared Test } \\
\hline & Positive (\%) & Negative (\%) & $x^{2}$ & df & $p$ Value \\
\hline \multicolumn{6}{|l|}{ Fever } \\
\hline Yes & $580(54.3)$ & $488(45.7)$ & 230.8 & 1 & $<0.001$ \\
\hline No & $787(28.2)$ & 2007 (71.8) & & & \\
\hline \multicolumn{6}{|l|}{ Dyspnea } \\
\hline Yes & $524(47.4)$ & $581(52.6)$ & 98.4 & 1 & $<0.001$ \\
\hline No & $848(30.6)$ & $1924(69.4)$ & & & \\
\hline \multicolumn{6}{|l|}{ Dry cough } \\
\hline Yes & $772(50.7)$ & $752(49.3)$ & 256.9 & 1 & $<0.001$ \\
\hline No & $600(25.5)$ & $1754(74.5)$ & & & \\
\hline \multicolumn{6}{|l|}{ Pharyngalgia } \\
\hline Yes & $392(45.5)$ & $469(54.5)$ & 49.9 & 1 & $<0.001$ \\
\hline No & $976(32.4)$ & $2032(67.6)$ & & & \\
\hline \multicolumn{6}{|l|}{ Diarrhea } \\
\hline Yes & $110(44.9)$ & $135(55.1)$ & 10.89 & 1 & $<0.001$ \\
\hline No & $1254(34.7)$ & $2355(65.3)$ & & & \\
\hline \multicolumn{6}{|l|}{ Headache } \\
\hline Yes & $279(40.6)$ & $409(59.4)$ & 9.6 & 1 & $<0.001$ \\
\hline No & $1083(34.2)$ & $2083(65.8)$ & & & \\
\hline \multicolumn{6}{|l|}{ Runny nose } \\
\hline Yes & $256(43.5)$ & $332(56.5)$ & 19.5 & 1 & $<0.001$ \\
\hline No & 1109 (33.9) & $2158(66.1)$ & & & \\
\hline \multicolumn{6}{|l|}{ Taste loss } \\
\hline Yes & $78(64.5)$ & $43(35.5)$ & 46.1 & 1 & $<0.001$ \\
\hline No & $1286(34.5)$ & 2446 (65.5) & & & \\
\hline \multicolumn{6}{|l|}{ Smell loss } \\
\hline Yes & $83(65.4)$ & 44 (34.6) & 46.1 & 1 & $<0.001$ \\
\hline No & $1280(34.4)$ & 2445 (65.6) & & & \\
\hline
\end{tabular}

$\chi^{2}$ : Chi-squared; df: degree of freedom. 


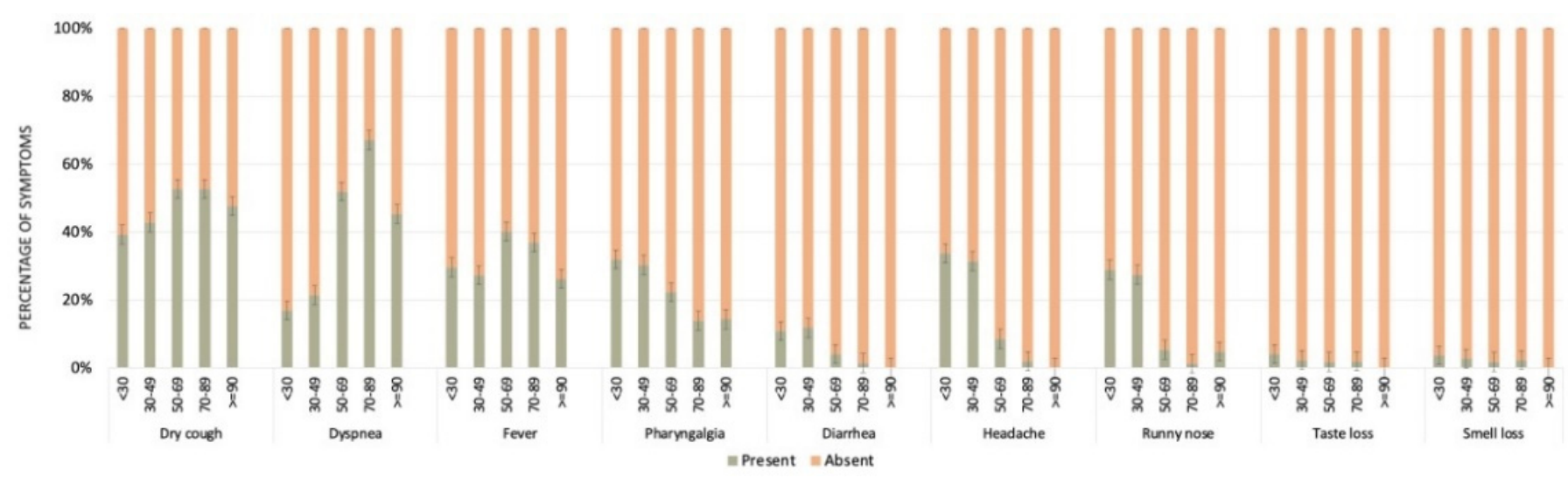

Figure 3. Proportion of individuals presenting the ten more frequent symptoms according to different age groups. Black dots represent the confidence intervals (high and low).

Table 3 and Figure 3 show the frequencies of clinical symptoms according to different age groups. Fever was commonly reported among patients aged $50-69$ years (50\%; 95\% Confidence Interval [CI]: 45.2-54.8\%), and was significantly higher than individuals $<30$ years, $30-49$, and $70-89$ years. On the other hand, dyspnea was more commonly reported among older patients, mainly aged $70-89$ years $(60.8 \%$, CI: $55.2-66.4 \%)$, followed by patients aged $50-69$ years $(49.6 \%$, CI: $44.8-54.4 \%)$, with a significant difference between them. Individuals aged 70-89 and 50-69 years also differed significantly from individuals aged $<30$ and $30-49$ years (15.4\%; CI: 9.9-20.8\% and $22.4 \%$; CI: $18,6-26.1 \%$, respectively).

Table 3. $p$ values of Chi-squared calculation between clinical symptom and age groups paired.

\begin{tabular}{|c|c|c|c|c|c|}
\hline \multirow{2}{*}{ Symptoms } & \multirow{2}{*}{ Age Groups } & \multicolumn{4}{|c|}{ Age Groups } \\
\hline & & $<30$ & $30-49$ & $50-69$ & $70-89$ \\
\hline \multirow{4}{*}{ Fever } & $30-49$ & 1.000 & & & \\
\hline & $50-69$ & 0.014 & 0.001 & & \\
\hline & $70-89$ & 0.800 & 0.745 & 0.011 & \\
\hline & $\geq 90$ & 0.621 & 0.614 & 1.000 & 0.695 \\
\hline \multirow{4}{*}{ Dyspnea } & $30-49$ & 0.069 & & & \\
\hline & $50-69$ & 0.000 & 0.000 & & \\
\hline & $70-89$ & 0.000 & 0.000 & 0.004 & \\
\hline & $\geq 90$ & 0.008 & 0.058 & 1.000 & 0.653 \\
\hline \multirow{4}{*}{ Dry cough } & $30-49$ & 0.910 & & & \\
\hline & $50-69$ & 0.003 & 0.000 & & \\
\hline & $70-89$ & 0.036 & 0.012 & 0.452 & \\
\hline & $\geq 90$ & 0.392 & 0.408 & 1.000 & 0.868 \\
\hline \multirow{4}{*}{ Pharyngalgia } & $30-49$ & 0.509 & & & \\
\hline & $50-69$ & 0.128 & 0.269 & & \\
\hline & $70-89$ & 0.001 & 0.001 & 0.033 & \\
\hline & $\geq 90$ & 0.701 & 0.856 & 1.000 & 1.000 \\
\hline \multirow{4}{*}{ Diarrhea } & $30-49$ & 0.065 & & & \\
\hline & $50-69$ & 0.192 & 0.000 & & \\
\hline & $70-89$ & 0.008 & 0.000 & 0.123 & \\
\hline & $\geq 90$ & 0.632 & 0.327 & 0.904 & 1.000 \\
\hline \multirow{4}{*}{ Headache } & $30-49$ & 1.000 & & & \\
\hline & $50-69$ & 0.000 & 0.000 & & \\
\hline & $70-89$ & 0.000 & 0.000 & 0.001 & \\
\hline & $\geq 90$ & 0.027 & 0.024 & 0.532 & 1.000 \\
\hline
\end{tabular}


Table 3. Cont.

\begin{tabular}{|c|c|c|c|c|c|}
\hline \multirow{2}{*}{ Symptoms } & \multirow{2}{*}{ Age Groups } & \multicolumn{4}{|c|}{ Age Groups } \\
\hline & & $<30$ & $30-49$ & $50-69$ & $70-89$ \\
\hline \multirow{4}{*}{ Runny nose } & $30-49$ & 0.932 & & & \\
\hline & $50-69$ & 0.000 & 0.000 & & \\
\hline & $70-89$ & 0.000 & 0.000 & 0.000 & \\
\hline & $\geq 90$ & 0.044 & 0.037 & 0.559 & 1.000 \\
\hline \multirow{4}{*}{ Taste loss } & $30-49$ & 0.110 & & & \\
\hline & $50-69$ & 0.000 & 0.010 & & \\
\hline & $70-89$ & 0.000 & 0.000 & 0.120 & \\
\hline & $\geq 90$ & 0.405 & 0.640 & 1.000 & 1.000 \\
\hline \multirow{4}{*}{ Smell loss } & $30-49$ & 0.582 & & & \\
\hline & $50-69$ & 0.000 & 0.000 & & \\
\hline & $70-89$ & 0.000 & 0.000 & 0.549 & \\
\hline & $\geq 90$ & 0.459 & 0.545 & 1.000 & 1.000 \\
\hline
\end{tabular}

Dry cough was more common in individuals aged 50-69 years (63.0\%, CI: 58.4-67.6\%) and $70-89$ years (59.9\%, CI: 54.3-65.6\%), with no significant difference between them. However, individuals aged $50-69$ and $70-89$ years old differed significantly from individuals aged $<30$ and $30-49$ years (49.4\%; CI: $41.8-57.0 \%$ and $50.3 \%$; CI: $45.8-54.8 \%$, respectively).

On the other hand, pharyngalgia was frequently reported by younger individuals $(<30$, $30-49,50-69$ years), but no significant differences were observed among them. Diarrhea was also frequently reported by younger individuals, aged $30-49$ years $(14.2 \%$; CI: 11.0 $17.3 \%)$, with a significant difference between individuals aged 50-69 years $(5.0 \%$; CI: $2.9-7.2 \%)$ and $70-89$ years $(2.4 ; \mathrm{CI}: 0.7-4.2 \%)$. The frequency of headache and runny nose was very similar, being more frequent in individuals up to 49 years old, but no significant differences were observed. Similar results were observed for taste and smell losses, those symptoms being frequently reported by individuals up to 49 years old, with no significant differences observed.

\subsection{Period of Onset of Clinical Symptoms until Laboratory Testing}

The mean and median times from notification of symptoms to laboratory testing for those individuals that tested positive for SARS-CoV-2 were 6.75 and 5.00 days, respectively. For those individuals that tested negative for SARS-CoV-2, the mean and median times from notification of symptoms to laboratory testing were 6.37 and 4.00 days, respectively. The analysis of correlation between individuals' age and the period from the onset of symptoms to laboratory testing was performed using the Spearman test (non-parametric). Although the $p \leq 0.001$, the correlation was low ( $r h o=0.12$ and $R 2=0.002)$, which cannot be considered significant.

\subsection{Factors Significantly Associated with SARS-CoV-2 Infection}

Statistical analysis revealed that healthcare professionals were less likely to test positive for SARS-CoV-2 (Odds Ratio $[\mathrm{OR}]=0.81, p<0.001$ ) (Table 4 ). In order to verify the association between other specific variables, new analyses were performed separating the healthcare professional's category from the remaining individuals.

Overall, individuals aged 50-89 years were more likely to test positive for SARS-CoV-2 $(\mathrm{OR}=1.86$ and 1.64 , respectively) (Table 4), being a more representative and significant variable among the general population of the study (Table 5). Although healthcare professionals in these aged 50-69 and 70-89 years were more affected, no statistical significance was observed (Table 6). 
Table 4. Characteristics associated with SARS-CoV-2 infection in all individuals $(n=3102)$ that attended referral hospitals in Southern Bahia State, Brazil.

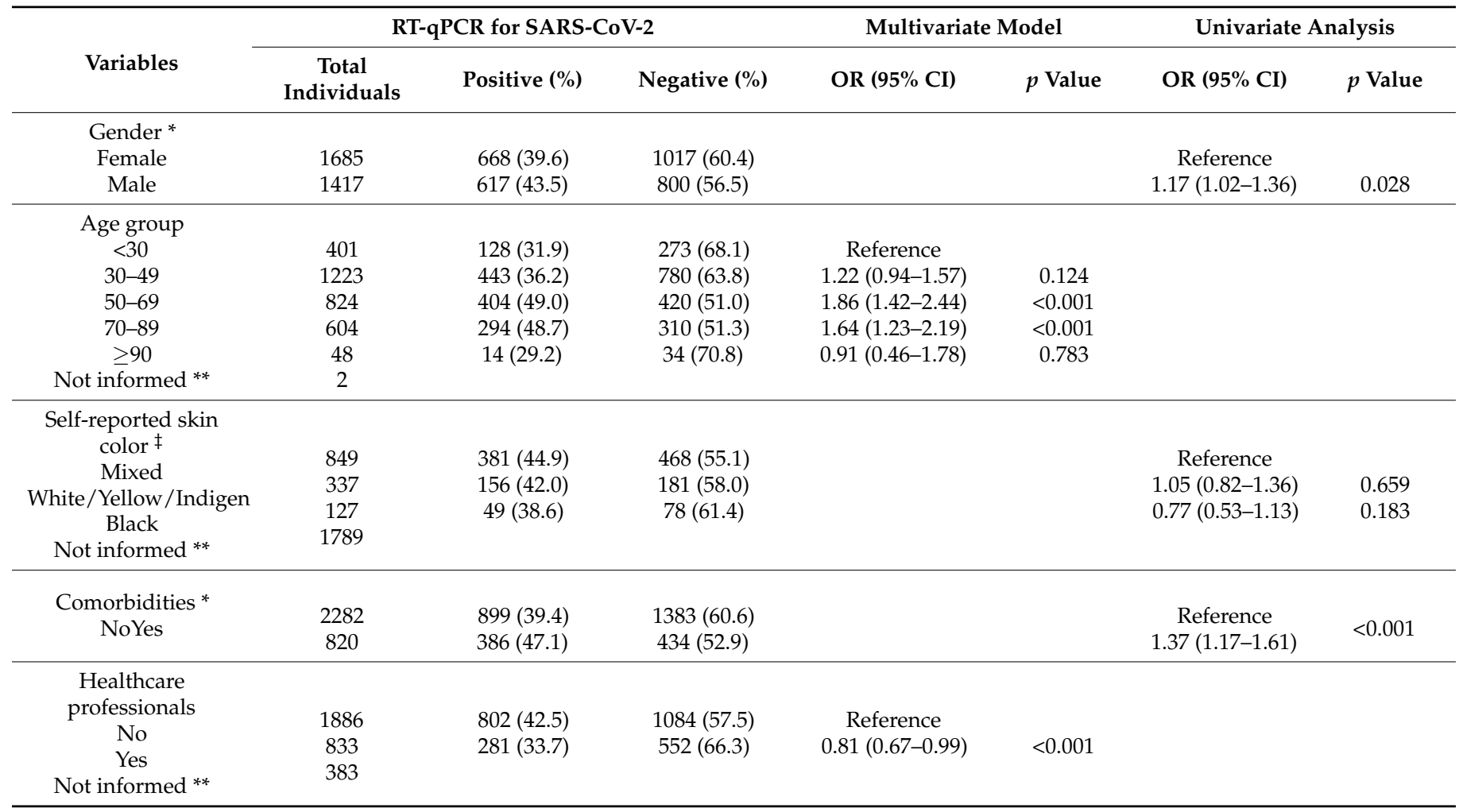

OR: Odds Ratio; CI: Confidence Interval. * Variables were not included in the multivariate model. ${ }^{* *}$ Not included in statistical analysis. $\ddagger$

Not included in statistical analysis due to the high number of individuals without information.

Table 5. Characteristics associated with SARS-CoV-2 infection in individuals $(n=1886)$ that attended referral hospitals in Southern Bahia State, Brazil.

\begin{tabular}{|c|c|c|c|c|c|c|c|}
\hline \multirow[b]{2}{*}{ Variables } & \multicolumn{3}{|c|}{ RT-qPCR for SARS-CoV-2 } & \multicolumn{2}{|c|}{ Multivariate Model } & \multicolumn{2}{|c|}{ Univariate Analysis } \\
\hline & $\begin{array}{c}\text { Total } \\
\text { Individuals }\end{array}$ & Positive (\%) & Negative (\%) & OR $(95 \% \mathrm{CI})$ & $p$ Value & OR $(95 \% \mathrm{CI})$ & $p$ Value \\
\hline \multicolumn{8}{|l|}{ Gender* } \\
\hline Female & 855 & $355(41.5)$ & $500(58.5)$ & & & Reference & \\
\hline Male & 1031 & $447(43.4)$ & $584(56.6)$ & & & $1.08(0.9-1.29)$ & 0.436 \\
\hline \multicolumn{8}{|l|}{ Age group } \\
\hline$<30$ & 221 & $73(33.0)$ & $148(67.0)$ & Reference & & & \\
\hline $30-49$ & 512 & $192(37.5)$ & $320(62.5)$ & $1.22(0.87-1.69)$ & 0.248 & & \\
\hline $50-69$ & 599 & $293(48.9)$ & $306(51.1)$ & $1.94(1.4-2.68)$ & $<0.001$ & & \\
\hline $70-89$ & 510 & $229(44.9)$ & $281(55.1)$ & $1.65(1.19-2.29)$ & $<0.001$ & & \\
\hline$\geq 90$ & 43 & $14(32.6)$ & $29(67.4)$ & $0.98(0.48-1.96)$ & 0.095 & & \\
\hline Not informed ${ }^{* *}$ & 1 & & & & & & \\
\hline \multicolumn{8}{|l|}{ Self-reported skin } \\
\hline color $\ddagger$ & 706 & $326(46.2)$ & $380(53.8)$ & & & Reference & \\
\hline $\begin{array}{c}\text { Mixed } \\
\text { White/Yellow/Indigen }\end{array}$ & 274 & $131(47.8)$ & $143(52.2)$ & & & $1.07(0.81-1.41)$ & 0.645 \\
\hline $\begin{array}{l}\text { White/ Yellow/Indigen } \\
\text { Black }\end{array}$ & 93 & $43(46.2)$ & $50(53.8)$ & & & $1.00(0.65-1.55)$ & 0.991 \\
\hline Not informed ** & 813 & & & & & & \\
\hline \multicolumn{8}{|l|}{ Comorbidities * } \\
\hline No & 1265 & $527(41.7)$ & $738(58.3)$ & & & Reference & \\
\hline Yes & 621 & $275(44.3)$ & $346(55.7)$ & & & $1.11(0.92-1.35)$ & 0.279 \\
\hline
\end{tabular}

OR: Odds Ratio; CI: Confidence Interval * Variables were not included in the multivariate model. ${ }^{* *}$ Not included in statistical analysis. ${ }^{\ddagger}$ Not included in statistical analysis due to the high number of individuals without information. 
Table 6. Characteristics associated with SARS-CoV-2 infection in healthcare professionals $(\mathrm{n}=833)$ that attended referral hospitals in Southern Bahia State, Brazil.

\begin{tabular}{|c|c|c|c|c|c|c|c|}
\hline \multirow[b]{2}{*}{ Variables } & \multicolumn{3}{|c|}{ RT-qPCR for SARS-CoV-2 } & \multicolumn{2}{|c|}{ Multivariate Model } & \multicolumn{2}{|c|}{ Univariate Analysis } \\
\hline & $\begin{array}{c}\text { Total } \\
\text { Individuals }\end{array}$ & Positive (\%) & Negative (\%) & OR $(95 \% \mathrm{CI})$ & $p$ Value & OR $(95 \%$ CI $)$ & $p$ Value \\
\hline \multicolumn{8}{|l|}{ Gender } \\
\hline Female & 637 & $224(35.2)$ & $413(64.8)$ & Reference & & & \\
\hline Male & 196 & $57(29.1)$ & 139 (70.9) & $0.76(0.53-1.07)$ & 0.112 & & \\
\hline \multicolumn{8}{|l|}{ Age group * } \\
\hline$<30$ & 142 & $42(29.6)$ & $100(70.4)$ & Reference & & Reference & 0.345 \\
\hline $30-49$ & 593 & $200(33.7)$ & $393(66.3)$ & $1.22(0.87-1.69)$ & 0.248 & $1.21(0.81-1.80)$ & 0.131 \\
\hline $50-69$ & 92 & $36(39.1)$ & $56(60.9)$ & $1.94(1.4-2.68)$ & $<0.001$ & $1.53(0.88-2.66)$ & 0.093 \\
\hline $70-89$ & 4 & $3(75.0)$ & $1(25.0)$ & $1.65(1.19-2.29)$ & $<0.001$ & $0.14(0.72-70.65)$ & 0.97 \\
\hline$\geq 90$ & 2 & 0 & $2(100.0)$ & $0.98(0.48-1.96)$ & 0.095 & 0 (0-Inf) & \\
\hline Not informed $* *$ & 0 & & & & & & \\
\hline \multicolumn{8}{|l|}{$\begin{array}{l}\text { Self-reported skin } \\
\text { color } \ddagger\end{array}$} \\
\hline Mixed & 83 & $23(27.7)$ & $60(72.3)$ & & & Reference & \\
\hline White/Yellow/Indigen & $\begin{array}{l}39 \\
31\end{array}$ & $14(35.9)$ & $25(64.1)$ & & & $1.46(0.65-3.29)$ & 0.36 \\
\hline $\begin{array}{c}\text { Black } \\
\text { Not informed }\end{array}$ & $\begin{array}{c}31 \\
680\end{array}$ & $3(9.7)$ & $28(90.3)$ & & & $0.28(0.08-1.01)$ & 0.052 \\
\hline \multicolumn{8}{|l|}{ Comorbidities * } \\
\hline No & 774 & 257 (33.2) & $517(66.8)$ & & & Reference & \\
\hline Yes & 59 & $24(40.7)$ & $35(59.3)$ & & & $1.38(0.8-2.37)$ & 0.248 \\
\hline
\end{tabular}

OR: Odds Ratio; CI: Confidence Interval. * Variables were not included in the multivariate model. ${ }^{*}$ Not included in statistical analysis. ${ }^{\ddagger}$ Not included in statistical analysis due to the high number of individuals without information.

Additionally, male individuals and having comorbidities were risk factors significantly associated with SARS-CoV-2 infection (OR $=1.17$ and $\mathrm{OR}=1.37$, respectively) in the univariate analysis (Table 4). However, the same variables were not statistically significant when analyzed separately between the healthcare professionals' group (Table 5) and the remaining individuals (Table 6).

\section{Discussion}

In this large study of adults attending referral hospitals with suspected SARS-CoV-2 infection, we showed that patients testing positive had substantial differences in gender, healthcare worker status, and the presence of comorbidities. As our study population was mostly composed of individuals with clinical suspicion for COVID-19 admitted at referral hospitals, or healthcare professionals working on the front line, high positivity for SARSCoV-2 infection was expected. The $41.4 \%$ detection rate of SARS-CoV-2, therefore, does not reflect the rate of infection in the general population, but in hospitalized individuals. Our results were also higher compared to the results from a study conducted in the UK that found a prevalence of $33.4 \%$ [25].

We also showed that, on average, the time of positivity in the RT-qPCR test after the onset of symptoms was 6.75 days with a median of 5 days. Our results corroborate with the time frame recommended by health authorities $[26,27]$ in which the laboratory tests should be performed 3-10 days after the onset of symptoms.

The most commonly reported symptoms were dry cough (41.4\%), dyspnea (33.8\%), and fever (28.9\%), which corroborates studies conducted in Detroit [28] and New York [29] that found higher prevalence. A study performed in China showed that the frequency of fever was also higher, ranging from $43.8 \%$ in patients at the time of admission at the hospital to $88.7 \%$ during hospitalization [30]. Furthermore, it is important to emphasize that some studies have suggested screening clinical symptoms such as fever and/or dry cough as a criterion to perform laboratory tests. Thus, a higher frequency of clinical symptoms could 
be expected [29]. However, our study population were laboratory tested regardless the presence of specific symptoms.

Our study also demonstrated that the main symptoms associated with COVID-19 were different according to different age groups, in which greater illness severity and longer duration have been associated in older individuals. However, in a study carried out in China, only sore throat showed a significant difference between individuals aged younger and older than 60 years [30]. Furthermore, we noted that there was no specific symptom related to individuals testing positive or not for SARS-CoV-2, reinforcing the importance of laboratory diagnosis. Indeed, our findings highlight the importance of a differential diagnosis for coronavirus disease once most of symptoms are similar to other respiratory infections $[7,8,10]$.

Regarding healthcare professionals, we found that nurses were more affected, corroborating other studies [31,32]. In fact, our data can be explained by long periods of direct contact with infected individuals, once nurses are one of the main healthcare professionals on the front line caring for patients with COVID-19 [31]. In addition, proportionally to other areas/professions, the nursing team is numerically the largest group of healthcare professionals in most hospitals.

It was found that individuals aged between 50 and 89 years were almost two times more likely to test positive for SARS-CoV-2 infection. Furthermore, male individuals and those with comorbidities were almost two times more likely to test positive for SARS-CoV-2 infection.

In our study, being a healthcare professional was a protective factor against SARS$\mathrm{CoV}-2$ infection $(\mathrm{OR}=0.81, p<0.001)$. A study conducted in Italy found that the profile of SARS-CoV-2 infection in COVID-19 units was almost the same as in other hospital units, suggesting that healthcare professionals working at COVID-19 units had a greater knowledge and risk perception compared to healthcare professionals at other hospital units [33]. One hypothesis that can help explain our findings is that healthcare professionals (mainly those working on the front line) have more and detailed access to health information, including prevention measures [33-35]. Additionally, healthcare professionals on the front line routinely use more effective protective personal equipment [36], and are more careful due to the constant exposure to individuals [33-35]. Furthermore, the advance of the pandemic has raised better perceptions of the risk among healthcare workers than the population in general, which could also help to explain our findings [34,35].

\section{Conclusions}

Data presented here are important to better understand the profile of SARS-CoV-2 infection within the hospital environment, provide insights into preventing future out-breaks of COVID-19, and contribute to mitigating the damage to healthcare systems. As most of patients evaluated here were asymptomatic, a comprehensive approach for symptom screening, routine testing, early identification, and contact tracing of more vulnerable individuals are important strategies to reduce transmission and stop the spread of the virus. This study also provides important and necessary information to health authorities and policymakers to improve control measures and management of the pandemic.

Author Contributions: Conceptualization, G.R.A. and S.R.G.; data curation, F.B.F., G.B.C., A.d.P.S., G.R.A., A.P.M.M., A.T.S.L., H.F.F., I.T.S.d.S., P.R.d.S., L.C.S., L.L.S.d.J., R.F., B.M.M., M.d.M.S., S.R.G. and L.E.B.; formal analysis, F.B.F., G.B.C., G.R.A., A.P.M.M., A.T.S.L., H.F.F., Í.T.S.d.S., P.R.d.S., L.C.S., L.L.S.d.J., R.F., B.M.M., M.d.M.S., S.R.G. and L.E.B.; funding acquisition, G.R.A. and S.R.G.; investigation, F.B.F., G.B.C., A.d.P.S., G.R.A., A.P.M.M., A.T.S.L., H.F.F., I.T.S.d.S., P.R.d.S., L.C.S., L.L.S.d.J., R.F., B.M.M., M.d.M.S., S.R.G. and L.E.B.; methodology, A.d.P.S., G.R.A. and S.R.G.; project administration, G.B.C., G.R.A., A.P.M.M. and S.R.G.; resources, G.R.A., A.P.M.M., M.d.M.S. and S.R.G.; supervision, G.B.C., A.d.P.S., G.R.A. and S.R.G.; visualization, F.B.F.; writing-original draft, F.B.F., G.B.C., A.d.P.S., G.R.A., A.P.M.M., A.T.S.L., H.F.F., I.T.S.d.S., P.R.d.S., L.C.S., L.L.S.d.J., R.F., B.M.M., M.d.M.S., S.R.G. and L.E.B.; writing-review and editing, F.B.F., G.B.C., A.d.P.S., G.R.A., 
A.P.M.M., A.T.S.L., H.F.F., Í.T.S.d.S., P.R.d.S., L.C.S., L.L.S.d.J., R.F., B.M.M., M.d.M.S., S.R.G. and L.E.B. All authors have read and agreed to the published version of the manuscript.

Funding: This research was funded by Programa Laboratórios de Campanha do Ministério de Ciência, Tecnologia e Inovação - MCTI/FINEP (0494/20 - 01.20.0026.00). and by Fundação de Amparo à Pesquisa do Estado da Bahia — Edital 02/2020 — PROGRAMA PESQUISA PARA O SUS: gestão compartilhada em saúde - PPSUS. The APC was funded by Universidade Estadual de Santa Cruz.

Institutional Review Board Statement: The study was conducted according to the guidelines of the Declaration of Helsinki, and approved by the Research Ethics Committee of Universidade Estadual de Santa Cruz under registration number CAAE: 39142720.5.0000.5526.

Informed Consent Statement: Not applicable.

Data Availability Statement: Not applicable.

Acknowledgments: We would like to thank the Laboratório Central de Saúde Pública da Bahia (LACEN/Bahia) for the assistance and support with the COVID-19 laboratory investigation.

Conflicts of Interest: The authors declare no conflict of interest.

\section{References}

1. Zhu, N.; Zhang, D.; Wang, W.; Li, X.; Yang, B.; Song, J.; Zhao, X.; Huang, B.; Shi, W.; Lu, R.; et al. A Novel Coronavirus from Patients with Pneumonia in China, 2019. N. Engl. J. Med. 2020, 382, 727-733. [CrossRef] [PubMed]

2. World Health Organization. Coronavirus Disease 2019 (COVID-19) Situation report-51. Geneva, Switzerland: World Health Organization. 2020. Available online: https:/ / www.who.int/docs/default-source/coronaviruse/situation-reports/20200311 -sitrep-51-covid-19.pdf?sfvrsn=1ba62e57_10pdficon (accessed on 11 June 2021).

3. Cucinotta, D.; Vanelli, M. WHO declares COVID-19 a pandemic. Acta Biomed. 2020, 91, 157-160. [CrossRef] [PubMed]

4. de Jesus, J.G.; Sacchi, C.; Candido, D.D.S.; Claro, I.M.; Sales, F.C.S.; Manuli, E.R.; da Silva, D.B.B.; de Paiva, T.M.; Pinho, M.A.B.; Santos, K.C.D.O.; et al. Importation and early local transmission of COVID-19 in Brazil, 2020. Revista do Instituto de Medicina Tropical de São Paulo 2020, 62, e30. [CrossRef]

5. Brasil Coronavírus Brasil. Available online: https:/ / covid.saude.gov.br/ (accessed on 12 June 2020).

6. Lai, C.C.; Liu, Y.H.; Wang, C.Y.; Wang, Y.H.; Hsueh, S.C.; Yen, M.Y.; Ko, W.C.; Hsueh, P.R. Asymptomatic Carrier State, Acute Respiratory Disease, and Pneumonia Due to Severe Acute Respiratory Syndrome Coronavirus 2 (SARS-CoV-2): Facts and myths. J. Microbiol. Immunol. Infect. 2020, 53, 404-412. [CrossRef]

7. Huang, C.; Wang, Y.; Li, X.; Ren, L.; Zhao, J.; Hu, Y.; Zhang, L.; Fan, G.; Xu, J.; Gu, X.; et al. Clinical features of patients infected with 2019 novel coronavirus in Wuhan, China. Lancet 2020, 395, 497-506. [CrossRef]

8. da Costa, K.V.; Carnaúba, A.T.L.; Rocha, K.W.; de Andrade, K.C.L.; Ferreira, S.M.; Menezes, P.D.L. Olfactory and taste disorders in COVID-19: A systematic review. Braz. J. Otorhinolaryngol. 2020, 86, 781-792. [CrossRef]

9. Centers for Disease Control and Prevention. Interim Clinical Guidance for Management of Patients with Confirmed Coronavirus Disease (COVID-19). 2020. Available online: https://www.cdc.gov/coronavirus/2019-ncov/hcp/clinical-guidancemanagement-patients.html (accessed on 2 August 2021).

10. Kariyawasam, J.C.; Jayarajah, U.; Riza, R.; Abeysuriya, V.; Seneviratne, S.L. Gastrointestinal manifestations in COVID-19. Trans. R. Soc. Trop. Med. Hyg. 2021. [CrossRef]

11. Jordan, R.E.; Adab, P.; Cheng, K.K. COVID-19: Risk factors for severe disease and death. BMJ 2020, 368, m1198. [CrossRef]

12. Wu, Z.; McGoogan, J.M. Characteristics of and Important Lessons from the Coronavirus Disease 2019 (COVID-19) Outbreak in China: Summary of a Report of 72314 Cases from the Chinese Center for Disease Control and Prevention. JAMA 2020, 323, 1239-1242. [CrossRef] [PubMed]

13. Rod, J.E.; Oviedo-Trespalacios, O.; Cortes-Ramirez, J. A brief-review of the risk factors for covid-19 severity. Revista de Saúde Pública 2020, 54, 60. [CrossRef]

14. Chen, T.; Wu, D.; Chen, H.; Yan, W.; Yang, D.; Chen, G.; Ma, K.; Xu, D.; Yu, H.; Wang, H.; et al. Clinical characteristics of 113 deceased patients with coronavirus disease 2019: Retrospective study. BMJ 2020, 368, m1091. [CrossRef]

15. Felsenstein, S.; Hedrich, C.M. COVID-19 in children and young people. Lancet Rheumatol. 2020, 2, e514-e516. [CrossRef]

16. Peckham, H.; de Gruijter, N.M.; Raine, C.; Radziszewska, A.; Ciurtin, C.; Wedderburn, L.R.; Rosser, E.C.; Webb, K.; Deakin, C.T. Male sex identified by global COVID-19 meta-analysis as a risk factor for death and ITU admission. Nat. Commun. 2020, 11, 1-10. [CrossRef]

17. Kissler, S.M.; Fauver, J.R.; Mack, C.; Olesen, S.W.; Tai, C.; Shiue, K.Y.; Kalinich, C.C.; Jednak, S.; Ott, I.M.; Vogels, C.B.F.; et al. Viral dynamics of acute SARS-CoV-2 infection and applications to diagnostic and public health strategies. PLoS Biol. 2021, 19, e3001333. [CrossRef]

18. Jorge, D.C.; Rodrigues, M.S.; Silva, M.S.; Cardim, L.L.; da Silva, N.B.; Silveira, I.H.; Silva, V.A.; Pereira, F.A.; de Azevedo, A.R.; Amad, A.A.; et al. Assessing the nationwide impact of COVID-19 mitigation policies on the transmission rate of SARS-CoV-2 in Brazil. Epidemics 2021, 35, 100465. [CrossRef] 
19. Nguyen, L.H.; Drew, D.A.; Graham, M.S.; Joshi, A.D.; Guo, C.-G.; Ma, W.; Mehta, R.S.; Warner, E.T.; Sikavi, D.R.; Lo, C.-H.; et al. Risk of COVID-19 among front-line health-care workers and the general community: A prospective cohort study. Lancet Public Heal. 2020, 5, e475-e483. [CrossRef]

20. Kameda, K.; Barbeitas, M.M.; Caetano, R.; Löwy, I.; de Oliveira, A.C.D.; Corrêa, M.C.D.V.; Cassier, M. Testing COVID-19 in Brazil: Fragmented efforts and challenges to expand diagnostic capacity at the Brazilian Unified National Health System. Cad. Saúde Pública 2021, 37, e00277420. [CrossRef]

21. Sacchi, C.T.; Gonçalves, M.G.; Lemos, A.P.S.; Almeida, S.C.G.; Caterino-De-Araujo, A.; Fukasawa, L.O. Comparative performances of seven quantitative Reverse-Transcription Polymerase Chain Reaction assays (RT-qPCR) for detecting SARS-CoV-2 infection in samples from individuals suspected of COVID-19 in São Paulo, Brazil. J. Clin. Virol. Plus 2021, 1, 100012. [CrossRef]

22. CDC 2019-Novel Coronavirus (2019-nCoV) Real-Time RT-PCR Diagnostic Panel. Available online: https://www.fda.gov/media/ 134922/download (accessed on 1 July 2020).

23. Cunningham, M. More than Just the Kappa Coefficient: A Program to Fully Characterize Inter-Rater Reliability between Two Raters. SAS Glob. Forum 2009, 242, 1-7.

24. Team, R. R: A language and environment for statistical computing, Vienna, R Foundation for Statistical Computing. 2009. Available online: http:/ / www.R-project.org (accessed on 1 September 2021).

25. Brendish, N.J.; Poole, S.; Naidu, V.V.; Mansbridge, C.T.; Norton, N.; Borca, F.; Phan, H.T.; Wheeler, H.; Harvey, M.; Presland, L.; et al. Clinical characteristics, symptoms and outcomes of 1054 adults presenting to hospital with suspected COVID-19: A comparison of patients with and without SARS-CoV-2 infection. J. Infect. 2020, 81, 937-943. [CrossRef]

26. Secretaria de Estado de Saúde. Centro de Operações de Emergências - COE/MS: Recomendações Técnicas COE sobre a Utilização dos Testes Diagnósticos para COVID-19 e para Retestagem Laboratorial diante de Resultados Divergentes de COVID-19. Available online: https:/ / www.saude.ms.gov.br/coe/notas-tecnicas-e-orientacoes (accessed on 5 May 2020).

27. Secretaria de Estado de Saúde. Diretoria de Vigilância Epidemiológica de Santa Catarina: MANUAL DE ORIENTAÇÕES DA COVID-19 (vírus SARS-CoV-2). Available online: https://www.saude.sc.gov.br/coronavirus/arquivos/Manual_08.09.pdf (accessed on 5 May 2020).

28. Suleyman, G.; Fadel, R.A.; Malette, K.M.; Hammond, C.; Abdulla, H.; Entz, A.; Demertzis, Z.; Hanna, Z.; Failla, A.; Dagher, C.; et al. Clinical Characteristics and Morbidity Associated with Coronavirus Disease 2019 in a Series of Patients in Metropolitan Detroit. JAMA Netw. Open 2020, 3, e2012270. [CrossRef]

29. Argenziano, M.G.; Bruce, S.L.; Slater, C.L.; Tiao, J.R.; Baldwin, M.R.; Barr, R.G.; Chang, B.P.; Chau, K.H.; Choi, J.J.; Gavin, N.; et al. Characterization and clinical course of 1000 patients with coronavirus disease 2019 in New York: Retrospective case series. BMJ 2020, 369, m1996. [CrossRef]

30. Khan, M.; Khan, H.; Khan, S.; Nawaz, M. Epidemiological and clinical characteristics of coronavirus disease (COVID-19) cases at a screening clinic during the early outbreak period: A single-centre study. J. Med. Microbiol. 2020, 69, 1114-1123. [CrossRef]

31. Liu, Y.; Mao, B.; Liang, S.; Yang, J.-W.; Lu, H.-W.; Chai, Y.-H.; Wang, L.; Zhang, L.; Li, Q.-H.; Zhao, L.; et al. Association between age and clinical characteristics and outcomes of COVID-19. Eur. Respir. J. 2020, 55, 2001112. [CrossRef] [PubMed]

32. Guan, W.-J.; Ni, Z.-Y.; Hu, Y.; Liang, W.-H.; Ou, C.-Q.; He, J.-X.; Liu, L.; Shan, H.; Lei, C.-L.; Hui, D.S.; et al. Clinical Characteristics of Coronavirus Disease 2019 in China. N. Engl. J. Med. 2020, 382, 1708-1720. [CrossRef] [PubMed]

33. Porru, S.; Carta, A.; Monaco, M.G.L.; Verlato, G.; Battaggia, A.; Parpaiola, M.; Cascio, G.L.; Pegoraro, M.; Militello, V.; Moretti, F; et al. Health Surveillance and Response to SARS-CoV-2 Mass Testing in Health Workers of a Large Italian Hospital in Verona, Veneto. Int. J. Environ. Res. Public Heal. 2020, 17, 5104. [CrossRef] [PubMed]

34. Borraz, L.A.M.; López, M.G.; Lasfuentes, P.C.; Pérez, E.G.; Domingo, C.O.; Marteles, J.L.B.; Gaspar, C.V.; de la Nieta, F.A.; Heres, A.S.; Forcada, Á.L.G.; et al. Prevalencia de infección por coronavirus SARS-CoV-2 en pacientes y profesionales de un hospital de media y larga estancia en España. Rev. Española Geriatría Gerontol. 2021, 56, 75-80. [CrossRef] [PubMed]

35. Gómez-Ochoa, S.A.; Franco, O.H.; Rojas, L.Z.; Raguindin, P.F.; Roa-Díaz, Z.M.; Wyssmann, B.M.; Guevara, S.L.R.; Echeverría, L.E.; Glisic, M.; Muka, T. COVID-19 in Healthcare Workers: A Living Systematic Review and Meta-analysis of Prevalence, Risk Factors, Clinical Characteristics, and Outcomes. Am. J. Epidemiol. 2020. [CrossRef]

36. De Carvalho, R.S.; Augusto, G.R.; Schoen, I.P.; De Oliveira, Y.S.; Zibordi, V.M.; Elias, Y.G.B.; Gobbi, D.R. Utilização de equipamentos de proteção individual em época de COVID-19. Glob. Acad. Nurs. J. 2020, 1, 6. [CrossRef] 